\title{
Effects of Triazolam on Brain Activity During Episodic Memory Encoding: A PET Study
}

\author{
Miriam Z. Mintzer, Ph.D., Roland R. Griffiths, Ph.D., Carlo Contoreggi, M.D., Alane S. Kimes, Ph.D.,
} Edythe D. London, Ph.D., and Monique Ernst, M.D., Ph.D.

It is well documented that acute administration of the benzodiazepine hypnotic drug triazolam (Halcion $\left.{ }^{\circledR}\right)$ impairs episodic memory encoding. We examined the neuroanatomical substrates of this effect in healthy adult volunteers using a double-blind, within-subject design. Following oral capsule administration $(0.25 \mathrm{mg} / 70 \mathrm{~kg}$ triazolam or placebo), regional cerebral blood flow ( $r C B F)$ was measured using positron emission tomography (PET) with ${ }^{15} \mathrm{O}-\mathrm{H}_{2} \mathrm{O}$ during the performance of semantic categorization, orthographic categorization, and visual fixation (resting) tasks. $r C B F$ associated with episodic memory encoding was measured by the difference in $r C B F$ during the orthographic categorization task relative to that during the semantic categorization task. Results in the placebo condition $(\mathrm{n}=9)$ replicated those of previous nonpharmacological encoding studies (activation in the left prefrontal cortex, cerebellum, anterior cingulate cortex, temporal cortex, and occipital cortex). Relative to placebo, results in the triazolam condition $(\mathrm{n}=6)$ revealed significantly impaired memory performance, and deactivation during encoding in a subset of areas shown previously to be associated with encoding (anterior cingulate cortex, cerebellum, and precuneus). Results are discussed in relation to triazolam's effects on mnemonic versus attentional processes.

[Neuropsychopharmacology 25:744-756, 2001] (C) 2001 American College of Neuropsychopharmacology. Published by Elsevier Science Inc.
KEY WORDS: Triazolam; Benzodiazepines; Episodic memory; Encoding; Positron emission tomography; Regional cerebral blood flow

From the The Johns Hopkins University School of Medicine (MZM,RRG), Baltimore, Maryland, USA; and National Institute on Drug Abuse-Intramural Research Program (CC,ASK,EDL,ME), Baltimore, Maryland, USA

Address correspondence to: Miriam Z. Mintzer, Ph.D., Department of Psychiatry and Behavioral Sciences, Behavioral Biology Research Center, The Johns Hopkins University School of Medicine, 5510 Nathan Shock Drive, Baltimore, Maryland 21224. Tel.:(410) 550-0529; Fax (410) 550-0030, e-mail: mmintzer@jhmi.edu

Received November 18, 2000; revised March 12, 2001; accepted March 15, 2001.

Online publication: 4/18/01 at www.acnp.org/citations/Npp 041801106 .
Benzodiazepine anxiolytic/hypnotic drugs, such as diazepam (Valium $\left.{ }^{\circledR}\right)$, alprazolam (Xanax $\left.\AA\right)$, lorazepam (Ativan $\AA)$, and triazolam (Halcion $\AA$ ), are among the most widely prescribed psychotropic medications. In addition to their anxiolytic and sedative properties, benzodiazepines also have memory- and cognitiveimpairing effects (for reviews see Curran 1991; Duka et al. 1996; Polster 1993). Acute benzodiazepine administration produces dose-related decrements in episodic memory encoding, while leaving retrieval of previously encoded material intact. Episodic memory refers to conscious long-term memory for a personally experienced event that is associated with a specific spatial and temporal context (Tulving 1972, 1983). Encoding refers to the cognitive processes engaged (either intentionally or unintentionally) during the initial event that lead to the creation of a representation or trace of the event in epi- 
sodic memory. Thus, if information is presented for study while a participant is under the influence of a benzodiazepine, subsequent memory for that information is impaired, even when memory testing occurs while the drug is no longer in the system; however, if information presented before drug administration is tested under the influence of a benzodiazepine, no impairment is observed.

Benzodiazepines act at specific receptor sites on the gamma-aminobutyric acid $(\mathrm{GABA})_{\mathrm{A}}$ receptor complex by facilitating the action of GABA, the primary inhibitory neurotransmitter in the central nervous system (CNS) (Mohler and Okada 1977; Squires and Braestrup 1977). Benzodiazepine receptors are distributed widely throughout the brain, and, therefore, the initial sites of benzodiazepine action in the brain are known (Fernandez-Lopez et al. 1997; Frey et al. 1996; Millet et al. 2000; Persson et al. 1985). Nonetheless, little is known about the brain circuitry affected by benzodiazepine administration during episodic memory encoding, because the distribution of such effects likely goes beyond the sites of initial receptor interactions.

Over the past decade, considerable progress has been made in identifying the brain regions involved in episodic memory encoding under nonpharmacological conditions using noninvasive functional neuroimaging techniques, such as positron emission tomography (PET) and functional magnetic resonance imaging (fMRI), which enable measurement of brain activity in vivo while a human subject performs specific tasks. Encoding has been investigated most commonly by comparing brain activity associated with a condition assumed to involve more encoding (e.g., semantic or conceptual categorization of words presented during an initial study phase) to that associated with a condition assumed to involve less encoding (e.g., orthographic or surface-level categorization of words) (Kapur et al. 1994, 1996) (cf. Craik and Lockhart 1972). Encoding also has been studied by identifying regions whose activity during encoding is correlated with successful performance on a subsequent memory test (Brewer et al. 1998; Fernandez et al. 1998; Wagner et al. 1998). Converging results from PET and fMRI studies indicate that episodic memory encoding involves increased activity (i.e., activation) in the prefrontal, medial temporal, anterior cingulate, and cerebellar regions (for a review see Cabeza and Nyberg 2000). Within the prefrontal cortex, the areas most commonly activated during encoding of verbal stimuli are Brodmann areas (BA) 9, 44, 45, 46, and 47 (cf. Buckner et al. 1999; Cabeza and Nyberg 2000). For verbal stimuli, the activation is consistently left-lateralized, supporting predictions of the HERA (hemispheric encoding/retrieval asymmetry) model that the left prefrontal cortex is more involved in encoding than the right prefrontal cortex (Nyberg et al. 1996, 1998; Tulving et al. 1994). Encoding- related medial temporal activation has shown a consistent lateralization pattern in which the activation is leftlateralized for verbal stimuli and bilateral for nonverbal stimuli (Kelley et al. 1998; Martin et al. 1997).

PET and fMRI also can be used to measure druginduced changes in brain activity (Friston et al. 1991, 1992; London and Morgan 1993; Stein et al. 2000). Friston and colleagues (1991) emphasize the utility of crossing behavioral and pharmacological challenges in PET studies; they note that in order to draw conclusions about the neuromodulation of behaviorally induced changes in brain activity, it is necessary to examine drug effects on brain activity during the performance of a particular behavioral task. However, to our knowledge, only a few studies (reviewed next) have examined benzodiazepines' effects on brain activity during performance of a memory task.

Roy-Byrne et al. (1993) examined effects of acute and chronic intravenous alprazolam administration on regional cerebral blood flow (rCBF, a measure of neural activity; Posner and Raichle 1994; Raichle 1994) with PET during the performance of tasks involving memory for word lists. However, the absence of a placebo control condition makes results of that study difficult to interpret. In a placebo-controlled PET study, Rosier et al. (1997) examined effects of oral diazepam on rCBF during performance of tasks involving memory for abstract visual shapes. Although the memory encoding phase was timed to coincide with the peak effect of diazepam, measurement of rCBF occurred 3 days later, during the retrieval phase; thus, this study does not provide information about brain regions affected by diazepam administration during episodic memory encoding. A recent rCBF-PET study (Coull et al. 1999) was designed to dissociate effects of diazepam $(10 \mathrm{mg})$ on episodic memory encoding (measured by a verbal task in which healthy adult participants were instructed to read visually presented words aloud and remember them for a future memory test) and executive function (measured by an alphabetical ordering task in which participants were presented with nonwords and instructed to rearrange and then read aloud the presented letters in alphabetical order) in a placebo-controlled design. The results revealed significantly decreased activity (i.e., deactivation) in the diazepam condition relative to placebo in the left dorsal prefrontal cortex during performance of the episodic memory encoding task and in the left frontal operculum during the executive function task. The authors concluded that effects of diazepam on executive function can be distinguished from its effects on episodic memory encoding. Although the generalizability of these results to other measures of executive function may be questioned, this study provides strong evidence that different effects of benzodiazepines can be dissociated using PET. Bagary et al. (2000) recently reported results of a placebo-controlled 
PET study designed to examine effects of midazolam $(.075 \mathrm{mg} / \mathrm{kg})$ on rCBF during an episodic memory encoding task in which healthy adult participants were instructed to remember auditorally presented words for a future memory test and to press a button after hearing each word. The results revealed significant deactivation in the midazolam condition during episodic memory encoding in the calcarine sulci bilaterally (BA 17), but not in the prefrontal cortex. An account of the differences between the Coull et al. (1999) and Bagary et al. (2000) studies in regions showing benzodiazepineinduced deactivation during encoding is not readily apparent, but may be related to methodological differences between the studies, such as the modality of stimulus presentation (i.e., visual vs. auditory) and the nature of the control task to which the encoding task was compared.

The present PET study was designed to examine effects of the benzodiazepine hypnotic triazolam (Halcion $\left.{ }^{\circledR}\right)$ on rCBF during episodic memory encoding. Both the Coull et al. (1999) and Bagary et al. (2000) studies utilized a mixed design in which the primary comparisons were made between $\mathrm{rCBF}$ during performance of tasks presented before versus after drug administration within a single session, and drug condition (drug versus placebo) was manipulated between subjects; the purpose of the placebo condition was to control for confounding effects of time within the session. The present study utilized a within-subject design in which each participant completed two separate experimental sessions at approximately 1-week intervals; single doses of triazolam $(0.25 \mathrm{mg} / 70 \mathrm{~kg})$ and placebo were administered in counterbalanced order across sessions. Triazolam was selected for study, because it produces memory-impairing effects (Mintzer et al. 1997; Mintzer and Griffiths 1999,2000$)$ and is more quickly eliminated $\left(t_{1 / 2}=\right.$ 1.1-4.4 hours; Friedman et al. 1986) than other benzodiazepines whose effects on memory also have been studied (e.g., diazepam and lorazepam). Different benzodiazepines generally produce qualitatively similar profiles of memory-impairing effects and only differ with respect to the time course of their effects. We hypothesized that results in the placebo condition would replicate those of nonpharmacological episodic memory encoding studies and that the triazolam-induced encoding impairment would be associated either with less activation than placebo or with deactivation in a subset of the encoding-associated brain regions.

\section{METHOD}

\section{Subjects}

Nine adult volunteers (four male) participated. Three of these participants did not complete the second of the two experimental sessions: two (one male and one fe- male) because of cyclotron failure during the second session, and one (female) because of a positive serum pregnancy test before the second session. All participants were right-handed (assessed by the PANESS scale; Werry and Aman 1976). Individuals with current acute or chronic medical problems (assessed by medical history, physical examination, and routine blood and urine screens), current or past histories of psychiatric disorders (assessed by a modified version of the semistructured psychiatric interview "Schedule for Affective Disorders and Schizophrenia," lifetime version; Endicott and Spitzer 1978), or contraindications to hypnotic drugs or to radiation exposure were excluded from participating. Because of concerns that effects of nicotine and nicotine withdrawal might affect brain activity and/or experimental task performance, individuals who smoked tobacco cigarettes or used other tobacco products were excluded from participation. Females who were pregnant (assessed by serum pregnancy tests during the initial screening interview and within $24 \mathrm{~h}$ before each experimental session) were excluded from participation. The nine participants ranged in age from 19 to 44 years (mean $=30$ ), in weight from 53 to $105 \mathrm{~kg}$ (mean = 74), and in estimated IQ score (assessed by the Shipley Institute of Living Scale; Zachary et al. 1985) from 92 to 117 (mean =108). Participants reported having completed 13.5 to 20 years of education (mean = 16). Five participants reported consuming caffeinated beverages delivering 77 to $200 \mathrm{mg}$ caffeine/day (mean = 122) whereas the other four reported drinking no caffeinated beverages. Four participants reported drinking alcohol socially. No participants reported significant histories of using psychoactive drugs.

This study was approved by the Institutional Review Boards of The Johns Hopkins Bayview Medical Center and the National Institute on Drug Abuse-Intramural Research Program. Participants gave their written informed consent before beginning the study and were paid for their participation. Participants were requested to refrain from using all psychoactive drugs (with the exception of caffeinated products) during the time they were participants in the study. At the start of each session, before drug administration, participants were tested for the presence of various drugs in urine (benzodiazepines, barbiturates, opioids, amphetamines, and cocaine) using an EMIT system (Syva Co., Palo Alto, $\mathrm{CA}$ ) and the presence of alcohol in expired air using a breathalyzer test.

\section{General Procedures}

Participants completed a total of one (three participants; see Subjects) or two (six participants) experimental outpatient sessions at approximately 1-week intervals. Following capsule administration, which took place at the Behavioral Pharmacology Research Unit (BPRU) of The 
Johns Hopkins University School of Medicine, participants were escorted to the National Institute on Drug Abuse-Intramural Research Program (NIDA-IRP) Brain Imaging Center, located on the ground floor of the Behavioral Biology Research Center building in which the BPRU is housed, by a BPRU staff member for the measurement of rCBF using PET. Each session involved six PET scans, each paired with the performance of one of three computerized tasks: semantic categorization, orthographic categorization, and resting (see Experimental Measures below); each task was performed twice during each session. The sequence of the three tasks across the six scans was $A B C A B C$, where each letter represents one of the three tasks. The three tasks were rotated among A, $B$, and $C$ in this sequence using a Latin Square such that across the six participants who completed both sessions, each task appeared equally often as the $\mathrm{A}, \mathrm{B}$, and $\mathrm{C}$ task in the sequence. The assignment of task to $A, B$, or $C$ for each participant remained constant across the two sessions. To synchronize PET scanning with the peak effect of triazolam based on previous behavioral (Mintzer et al. 1997; Mintzer and Griffiths 1999) and pharmacokinetic (Friedman et al. 1986) studies, the first PET scan took place approximately $70 \mathrm{~min}$ after drug administration. Each PET scan involved the injection of $10 \mathrm{mCi}$ of ${ }^{15} \mathrm{O}-$ $\mathrm{H}_{2} \mathrm{O}$, the most commonly used radioactive tracer in cognitive studies. To ensure that participants were fully engaged in the cognitive task during the acquisition of PET data, each task was initiated $30 \mathrm{sec}$ before the injection; task performance also continued for several seconds after PET data acquisition. The acquisition of PET data for rCBF measurement began after the bolus of radioactivity reached the brain; PET data were acquired for $60 \mathrm{~s}$ during each scan. Each scan was followed by a 10-12 min interval during which the participant remained in the supine position in the scanner. After completion of the sixth PET scan, participants were escorted back to the BPRU where they completed a memory test for the words presented during the memory encoding task.

The experimental measures consisted of performance on the computerized tasks conducted during the PET scans and on the final memory test performed after completion of the scans. The tasks were administered on a Macintosh microcomputer, and participant responses were made via the computer mouse using the participant's right (i.e., dominant) hand. Stimuli presented while the participant was in the PET scanner were projected onto a large LCD monitor connected to the microcomputer. In addition, participants' subjective and physiological states were monitored periodically during the session.

\section{Drug Administration}

The two drug conditions were placebo and $0.25 \mathrm{mg} / 70$ $\mathrm{kg}$ triazolam. Single oral doses were administered in a double-blind, cross-over design in counterbalanced or- der across the six participants who completed both experimental sessions; the three participants who failed to complete the second session (see Subjects) all had been randomly assigned to receive placebo during their first session. Triazolam doses were prepared from commercially available $0.125-\mathrm{mg}$ tablets (Halcion ${ }^{\circledR}$; UpJohn Company, Kalamazoo, MI). Capsules were crushed and doses were adjusted by participant body weight. All doses were dispensed in size 0 capsules. Lactose was used to fill the remainder of each capsule. Placebo capsules contained only lactose. Capsules were taken orally with approximately $150 \mathrm{ml}$ of water.

\section{Experimental Measures}

Semantic/Orthographic Categorization Tasks: Stimulus materials. The stimulus materials and procedures used for these tasks were carefully selected based on pilot work. The stimuli for each session consisted of a unique set (i.e., no stimulus was repeated across sessions) of 72 common concrete nouns containing 4 to 8 letters selected from the Thorndike and Lorge (1944) word corpus; the sets were equated across the two sessions for mean word frequency in the language (Thorndike and Lorge 1944) and word length. (The 72word stimulus set [critical stimuli] was used for presentation during the 60-s PET data acquisition period and during the final recognition memory test as described below. An additional set of words [noncritical stimuli] was selected based on similar criteria to be presented before and after the data acquisition period across PET scans [see General Procedures]; the noncritical stimuli were not included in the recognition memory test.) The 72-word stimulus set assigned to each session was divided into six subsets of 12 words each, with the constraint that the subsets were equated for mean word frequency and word length. Each 12-word subset consisted of three words in each of the following four categories: words representing artificial or man-made objects/containing the letter "a" (e.g., "ball"), words representing artificial objects/not containing the letter "a" (e.g., "sock"), words representing natural objects/ containing the letter "a" (e.g., "leaf"), and words representing natural objects/not containing the letter "a" (e.g., "plum"). Two subsets were used in the semantic categorization condition (i.e., one 12-word subset presented during the 60-s PET data acquisition period of each of the two scans assigned to this condition), two in the orthographic categorization condition (i.e., one 12word subset presented during the PET data acquisition period of each of the two scans assigned to this condition), and two were used as new words presented only during the recognition memory test ( 24 words total) (see Procedures below). The subsets were rotated among these three conditions (i.e., semantic categorization, orthographic categorization, new) using a Latin 
Square such that across participants within each drug order condition $(n=6)$, each subset appeared equally often in each of the three conditions.

Semantic/Orthographic Categorization Tasks: Procedures. Participants were familiarized with the procedures for these tasks before the first session, at the initial screening interview in which they completed an abbreviated version of the tasks (with a different stimulus set than that used for the two experimental sessions). During the screening interview as well as during each experimental session, before beginning each task, the research assistant read aloud task instructions, which also appeared on the computer monitor. The semantic and orthographic categorization tasks were identical in terms of sensory input and motor output and only differed with respect to the cognitive demands on participants. For both tasks, during the PET data acquisition period of each scan, 12 words were presented on the computer monitor one at a time, and participants were asked to respond by using the computer mouse to click on the appropriately labeled button (i.e., "artificial," "natural," "a," or "no a"; see below) on the monitor. Each word was displayed on the monitor for two seconds; the appearance of the next stimulus was contingent on the participant's response with the constraint that the interstimulus interval (ISI) could be no less than 3 seconds (even if the participant responded before that time), and no more than 5 seconds (even if the participant did not respond within that time frame). Given that triazolam has been shown to increase reaction time (RT), self-paced presentation was used to allow participants sufficient time to process each stimulus in both drug conditions. However, to minimize variability in presentation pace, the ISI was constrained within a fixed range (i.e., $3-5$ s), the parameters of which were carefully selected based on pilot work. (Stimulus presentation was continuous [from $30 \mathrm{~s}$ before the injection until several s after PET data acquisition] such that all participants received all stimuli, regardless of presentation pace. Although the critical 12word subset was timed to be presented during the 60-s PET data acquisition period, given the variability in stimulus presentation pace, it was not possible to ensure this timing. However, as described above, the noncritical stimuli presented before and after the critical stimuli were selected based on similar criteria to the critical stimuli. Most importantly, data on the ISI indicate that we were successful in minimizing variability in presentation pace: Mean ISI [averaged across task] was $3.02 \mathrm{~s}$ in both the triazolam and placebo conditions, and no participant failed to respond to any stimulus within the 5-s time frame in either drug condition.) In the semantic categorization task, participants were instructed to categorize each word as representing an artificial (i.e., man-made) or natural object, and were
Table 1. Regions of Activation During the Semantic Categorization Task Relative to Orthographic Categorization in the Placebo Condition $(n=6)$

\begin{tabular}{|c|c|c|c|c|c|c|}
\hline \multirow[b]{2}{*}{ Region } & \multirow[b]{2}{*}{ BA } & \multicolumn{4}{|c|}{ Peak Coordinates } & \multirow{2}{*}{$\begin{array}{l}\text { Cluster } \\
\text { Size (\# of } \\
\text { Voxels) }\end{array}$} \\
\hline & & $\mathbf{x}$ & $\mathbf{y}$ & $\mathbf{z}$ & Z-score & \\
\hline Left cerebellum & & -54 & -58 & -22 & 3.50 & 17 \\
\hline Left cerebellum & & -52 & -66 & -36 & 3.25 & 10 \\
\hline Left middle temporal & 21 & -52 & 0 & -12 & 3.19 & 2 \\
\hline
\end{tabular}

Note: Coordinates (mm) from the Talairach and Tournoux (1988) atlas; positive values refer to regions to the right of $(\mathrm{x})$, anterior to $(\mathrm{y})$, and superior to $(\mathrm{z})$ the anterior commissure. BA refers to the approximate Brodmann area corresponding to the atlas coordinates.

informed that their memory for these words would be tested later in the session. In the orthographic categorization task, participants were instructed to determine whether or not each word contained the letter "a," and were informed that their memory for these words would not be tested. Given the reliable finding that recognition memory performance is better following semantic/deep encoding than following orthographic/ shallow encoding ("level of processing effect"; Craik and Lockhart 1972), the semantic categorization condition was assumed to involve greater memory encoding than the orthographic categorization condition. It should be noted that in "level of processing" studies, participants typically are not informed during the study phase that their memory will be tested; however, in the context of the present repeated measures design in which participants would become aware of memory testing later in the session, we considered it important to inform participants of the testing during the study phase of the first session so that their level of knowledge would be equated across sessions. Given that previous studies involving intentional encoding have shown reliable "level of processing" effects, we do not believe these instructions should significantly affect interpretation of the results. In the recognition memory test (conducted $45 \mathrm{~min}$ after completion of the PET scans), participants were presented with the 24 words from the semantic categorization scans (old), along with 24 words not presented previously in the session (new); for each word, participants were asked to determine whether it was old or new. Each test word remained on the screen until the participant responded, and RT was not measured. The purpose of the memory test was to provide a behavioral assessment of participants' memory for the words presented during the semantic categorization scans as a function of drug condition. (Although the participant's drug effect during the recognition memory test was generally reduced relative to its peak magnitude [during the PET scans], it was still present. However, given that triazolam has been shown to impair encoding but not retrieval, we believe any tri- 
azolam-induced impairment observed on recognition memory performance likely reflected an impairment in encoding rather than retrieval.) Consistent with the instructions given to participants, memory for the words presented during the orthographic categorization scans was not tested (in order to ensure greater encoding in the semantic categorization task).

Resting Task. During the resting task, participants were instructed to fixate on an immobile cross appearing on the computer monitor. The purpose of the resting task was to provide quality control for the PET procedures; data from this task are not reported.

\section{PET Procedures}

Imaging was performed using a Siemens/CTI ECAT exact HR+ PET scanner in three-dimensional mode with a $15.5-\mathrm{cm}$ axial field of view. Before the first scan, an indwelling flexible catheter was placed in the antecubital fossa of the participant's left arm and remained in place throughout the PET portion of the session for ${ }^{15} \mathrm{O}-\mathrm{H}_{2} \mathrm{O}$ administration. The participant's head was aligned in the supine position in the PET scanner, and a thermoplastic mask, custom-made for each participant, was used to minimize head movement. A transmission scan was performed to be used for correction of absorption and attenuation of annihilation photons (gamma rays) due to their interactions with tissue. Attenuation-corrected data were reconstructed into 63 image planes, with a resulting resolution of $6 \mathrm{~mm}$ at full-width-half-maximum (FWHM). Arterial blood was not sampled, and absolute rates of rCBF were not determined.

\section{Data Analysis}

Cognitive Data. Data from the semantic and orthographic categorization tasks (i.e., proportions of words correctly categorized as artificial versus natural or as containing versus not containing the letter "a"), averaged across the two scans associated with each task, were analyzed by a $2 \times 2$ repeated measures analysis of variance (ANOVA) with drug condition (triazolam vs. placebo) and task (semantic vs. orthographic categorization) as factors. Data from the final recognition memory test (which included words from the semantic categorization task only) were analyzed by performing paired $t$-tests as a function of drug condition on the hit rate (proportion of old items correctly recognized as old), false alarm rate (proportion of new items incorrectly recognized as old), and $\mathrm{d}^{\prime}$ ( $z$ score of false alarm rate minus $z$ score of hit rate; signal detection measure of sensitivity).

PET Data. To correct for head motion, all images of a participant within a single session were realigned to those of his or her first scan in that session using the Automated Image Registration Program (AIR; Woods et al. 1992b). The following standardized procedures were then applied to the images using statistical parametric mapping software developed at the Wellcome Department of Cognitive Neurology, London (SPM99; Friston et al. 1995). To adjust for interparticipant differences in global radioactivity counts and intersession differences in global counts within a participant, the mean of the counts of all voxels common to all registered scans of a participant in a given session (i.e., global counts) were used to normalize the participant's regional data for that session using proportional scaling. The registered data were resized and reshaped to a standard stereotaxic atlas (Talairach and Tournoux 1988) based on landmarks inferred from the PET images. Data were then smoothed with a 3-dimensional Gaussian filter (10 $\mathrm{mm}, 10 \mathrm{~mm}$, and $10 \mathrm{~mm}$ in the $\mathrm{x}-, \mathrm{y}^{-}$, and z-planes, respectively) to reduce high-frequency noise and the effects of individual differences in gyral anatomy. Data from the two scans paired with each task (i.e., semantic categorization, orthographic categorization, and resting) were averaged using an adjusted mean to yield one image per task. Finally, a voxel-by-voxel analysis was performed for all planes common to all participants (from $28 \mathrm{~mm}$ below to $54 \mathrm{~mm}$ above the anterior-posterior intercommissural line). As described below, planned linear contrasts were tested; for each contrast, the value of $t$ for each voxel was calculated and transformed to a normal standard distribution. The resulting $z$ statistics showing all voxels significantly activated at $p<$ .001 (uncorrected for multiple comparisons) were mapped, and stereotaxic coordinates of the epicenters (i.e., maxima) of areas of significance were determined. Although an uncorrected threshold of 0.001 is relatively liberal, it has been shown in phantom activation simulations to adequately protect from false-positives without correcting for multiple comparisons (Bailey et al. 1991) and has been used in other cognitive functional neuroimaging studies.

Given that semantic categorization involves more elaborate encoding than orthographic categorization (cf. Craik and Lockhart 1972), subtraction of the rCBF during the orthographic categorization task from that during the semantic categorization task was considered a measure of the $\mathrm{rCBF}$ associated with episodic memory encoding. Thus, the brain regions that mediate encoding were defined in planned contrasts as those which exhibited significantly increased activity (i.e., activation) during performance of the semantic categorization task relative to the orthographic categorization task in the placebo condition. Brain regions exhibiting changes in activity in response to triazolam during memory encoding were identified by examining the interaction in rCBF between drug condition (triazolam vs. placebo) and task (semantic vs. orthographic categori- 
Table 2. Regions of Activation During the Semantic Categorization Task Relative to Orthographic Categorization in the Placebo Condition $(n=9)$

\begin{tabular}{|c|c|c|c|c|c|c|}
\hline \multirow[b]{2}{*}{ Region } & \multirow[b]{2}{*}{ BA } & \multicolumn{4}{|c|}{ Peak Coordinates } & \multirow{2}{*}{$\begin{array}{l}\text { Cluster Size } \\
\text { (\# of Voxels) }\end{array}$} \\
\hline & & $\mathbf{x}$ & $\mathbf{y}$ & $\mathbf{z}$ & Z-score & \\
\hline Left cerebellum & & -50 & -64 & -34 & 3.91 & 153 \\
\hline Left inferior temporal gyrus & 20 & -50 & -38 & -16 & 3.82 & 33 \\
\hline Left lingual gyrus & $17 / 18$ & -14 & -74 & 6 & 3.65 & 19 \\
\hline Left medial frontal & $6 / 8$ & -8 & 20 & 46 & 3.58 & 28 \\
\hline Right middle temporal gyrus & $19 / 39$ & 42 & -74 & 14 & 3.45 & 4 \\
\hline Left medial frontal & 9 & -2 & 50 & 24 & 3.42 & 26 \\
\hline Left cingulate gyrus & 32 & -12 & 30 & 28 & 3.35 & 4 \\
\hline Left inferior frontal gyrus & 47 & -54 & 36 & -10 & 3.17 & 3 \\
\hline
\end{tabular}

Note: Coordinates $(\mathrm{mm})$ from the Talairach and Tournoux (1988) atlas; positive values refer to regions to the right of (x), anterior to (y), and superior to $(\mathrm{z})$ the anterior commissure. BA refers to the approximate Brodmann area corresponding to the atlas coordinates.

zation). This was accomplished in SPM using a random effects model that analyzed the difference between the triazolam and placebo conditions in the difference in rCBF between the semantic and orthographic categorization tasks. We hypothesized that the triazolaminduced encoding impairment would be associated either with less activation or with deactivation in a subset of the encoding-associated brain regions. Thus, the primary interest was in regions exhibiting triazolam-induced decreases in this interaction (i.e., an SPM contrast defined by the following weights: placebo/semantic categorization $=1$; placebo/orthographic categorization $=-1$; triazolam $/$ semantic categorization $=-1$; triazolam/orthographic categorization $=1$ ) [although triazolam-induced increases were also analyzed (i.e., an SPM contrast defined by the following weights: placebo/semantic categorization $=-1$; placebo/orthographic categorization $=1$; triazolam $/$ semantic categorization $=1$; triazolam $/$ orthographic categorization $=$ -1)]. (It should be noted that "activation" and "deactivation" are relative terms. Given our theoretical interest in episodic memory encoding and in the decreases in brain activity associated with triazolam-induced encoding impairment, we have followed the convention adopted in previous encoding studies of using activation to refer to increased activity in the semantic categorization task relative to orthographic categorization. Accordingly, deactivation in the triazolam condition [measured by the interaction between drug condition and task] is used to refer to decreased activity in the semantic categorization task relative to orthographic categorization under triazolam relative to placebo conditions. However, in an alternative theoretical framework, increased activity in the orthographic categorization task relative to semantic categorization may be viewed as activation, and triazolam may be viewed as producing increased activity in the orthographic categorization task relative to semantic categorization rather than $d e-$ creased activity in the semantic categorization task relative to orthographic categorization.)

\section{RESULTS}

Except where otherwise noted, reported results include only data from the six participants who completed both experimental sessions.

\section{Activation in the Placebo Condition: PET Data}

Brain regions that exhibited significant activation during the semantic categorization task relative to the orthographic categorization task in the placebo condition were the left cerebellum and left temporal cortex (BA 21) (see Table 1). Several areas in the left prefrontal cortex (BA 10, 44, 45/46, 47) also showed increased activity during semantic relative to orthographic categorization, but the effects did not reach statistical significance $(p<.005)$. The failure to demonstrate significant prefrontal activation during semantic categorization may be related to low statistical power attributable to the small sample size $(n=6)$. This possibility is supported by results of analyses conducted on a larger sample ( $n$ $=9$ ), which included the three participants who completed only the placebo session (see Subjects, Drug Administration); in addition to the cerebellum, anterior cingulate cortex, temporal cortex, and occipital cortex, several areas in the left prefrontal cortex (BA 6/8, 9, 47) exhibited significant activation during semantic categorization in this sample (see Table 2, Figure 1). The small size of the clusters in both samples also seems to be related to low power; when the threshold is lowered from $p<.001$ to $p<.01$, the cluster sizes substantially increase (e.g., the cluster size of the activation in the left inferior frontal gyrus/BA 47 in Table 2 increases from 3 to 159 voxels).

\section{Triazolam-Induced Changes: Cognitive Data}

The mean proportions of words correctly categorized on the semantic and orthographic categorization tasks 
Table 3. Mean (Standard Deviation) Hit Rate, False Alarm Rate, and d' on the Recognition Memory Test as a Function of Drug Condition $(n=6)$

\begin{tabular}{lccc}
\hline Drug Condition & Hit Rate & False Alarm Rate & $\mathbf{d}^{\prime}$ \\
\hline Placebo & $0.79(0.15)$ & $0.17(0.09)$ & $1.90(0.31)$ \\
Triazolam & $0.64(0.25)$ & $0.25(0.14)$ & $1.22(0.51)$ \\
\hline
\end{tabular}

were quite high in both the placebo (1.0 for semantic categorization and 0.98 for orthographic categorization) and triazolam ( 0.97 for semantic categorization and 0.98 for orthographic categorization) conditions; the $2 \times 2$ ANOVA revealed no significant effects. Data from the final recognition memory test are shown in Table 3 . Recognition memory performance was impaired in the triazolam condition relative to placebo; mean hit rate and $\mathrm{d}^{\prime}$ were both lower in the triazolam condition relative to placebo whereas mean false alarm rate was higher in the triazolam condition. The difference between drug conditions was significant for hit rate $[(t(5)=$ 2.92, $p=.03]$ and $\mathrm{d}^{\prime}[(t(5)=2.57, p=.03]$, but not for false alarm rate $[p=.19]$. Given that previous studies have reported reliable effects of triazolam on false alarm rate at this dose (e.g., Mintzer and Griffiths 1999, 2000), the failure to demonstrate a significant effect of triazolam on false alarm rate in the present study is likely related to low statistical power associated with the small sample size $(n=6)$.

\section{Triazolam-Induced Changes: PET Data}

Brain regions that exhibited significant deactivation in response to triazolam during memory encoding [measured by the interaction in rCBF between drug condition (triazolam vs. placebo) and task (semantic vs. orthographic categorization)] were the left precuneus (BA 7), right anterior cingulate cortex (BA 32), and right cerebellum (see Table 4, Figure 2). The left anterior cingulate cortex (BA 32; cingulate gyrus; coordinates $-2,38$, $-8)$ also showed decreased activity, but without reaching significance $(p=.003)$. In addition, the right prefrontal cortex (BA 45; inferior frontal gyrus) showed decreased activity without reaching significance $(p=$ .002). Again, the small size of the clusters seems to be related to low power; when the threshold is lowered from $p<.001$ to $p<.01$, the cluster sizes substantially increase (e.g., the cluster size of the activation in the right anterior cingulate cortex/BA 32 increases from 7 to 112 voxels). The only region that exhibited significant activation in response to triazolam during encoding was the right frontal cortex (BA 4; paracentral lobule; peak coordinates $2,-28,58)$.

\section{DISCUSSION}

\section{Activation in the Placebo Condition}

As predicted, results in the placebo condition (Tables 1,2; Figure 1) replicated those of nonpharmacological episodic memory encoding studies. The finding of leftlateralized activation in the prefrontal cortex (significant only in the larger sample: Table 2; Figure 1) during encoding (measured by the difference in rCBF during orthographic relative to semantic categorization) is consistent with predictions of the HERA (hemispheric encoding/retrieval asymmetry) model that the left prefrontal cortex is more involved in encoding than the right prefrontal cortex (Nyberg et al. 1996, 1998; Tulving et al. 1994). The finding of encoding-associated activation in the cerebellum is also consistent with results of previous verbal encoding studies (Fernandez et al. 1998; Kopelman et al. 1998). The cerebellum was traditionally viewed as a structure involved exclusively in motor processes. Although the exact nature of the cerebellum's role in cognitive functions remains to be elucidated, recent anatomical and functional neuroimaging evidence indicate that the cerebellum has extensive neural projections to cognitive areas in the prefrontal cortex and plays an important role in many cognitive processes, including episodic memory encoding (for a review see Leiner et al. 1995). Consistent with results of several encoding studies (Dolan and Fletcher 1997; Grady et al. 1998; Kapur et al. 1996), activation during encoding was observed in the left lateral temporal cortex (i.e., BA 20, 21). Left lateral temporal activation (particularly in BA 21) is also commonly observed during tasks involving retrieval from semantic memory (Demonet et al. 1994; Vandenberghe et al. 1996; Wise et al. 1991); semantic memory refers to memory for culturally shared knowledge (e.g., meanings of words, facts) not associated with a specific spatial and temporal context (Tulving 1972, 1983). Not surprisingly, the regions acti-

Table 4. Regions of Deactivation in the Triazolam Condition Relative to Placebo During Semantic Categorization [Measured by the Interaction in $\mathrm{rCBF}$ Between Drug Condition (Triazolam vs. Placebo) and Task (Semantic vs. Orthographic Categorization)] $(n=6)$

\begin{tabular}{lrrrrrrr}
\hline & & \multicolumn{4}{c}{ Peak Coordinates } & \\
\cline { 3 - 6 } Region & BA & $\mathbf{x}$ & $\mathbf{y}$ & $\mathbf{z}$ & Z-score & $\begin{array}{c}\text { Cluster Size } \\
\text { (\# of Voxels) }\end{array}$ \\
\hline $\begin{array}{l}\text { Left precuneus } \\
\text { Right cingulate }\end{array}$ & 7 & -10 & -74 & 44 & 3.76 & 12 \\
$\begin{array}{l}\text { gyrus } \\
\text { Right cerebellum }\end{array}$ & 32 & 2 & 46 & 0 & 3.39 & 7 \\
\hline
\end{tabular}

Note: Coordinates (mm) from the Talairach and Tournoux (1988) atlas; positive values refer to regions to the right of $(\mathrm{x})$, anterior to $(\mathrm{y})$, and superior to $(\mathrm{z})$ the anterior commissure. BA refers to the approximate Brodmann area corresponding to the atlas coordinates. 

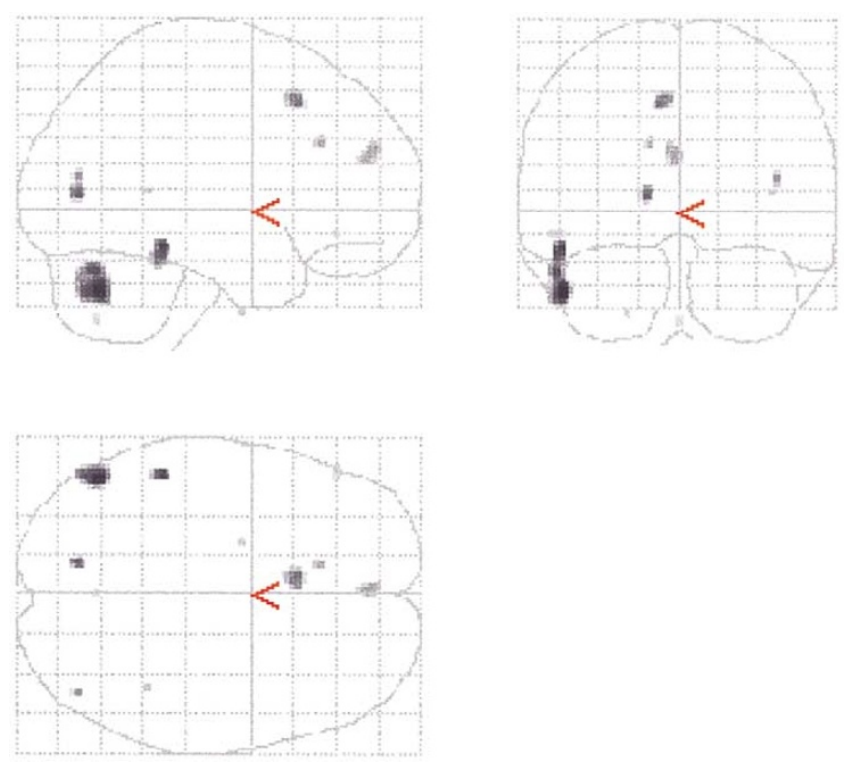

Figure 1. Activation during the semantic categorization task relative to orthographic categorization in the placebo condition $(n=9)$. Distributions of significantly activated voxels are shown as integrated projections onto sagittal (top left), coronal (top right) (image right is participant's right), and transverse (bottom) (image top is participant's left) views of the brain. vated during episodic memory encoding have considerable overlap with those implicated in retrieval from semantic memory (probably because encoding frequently involves retrieval of conceptual information from semantic memory). In our larger sample $(n=9$; Table 2, Figure 1), encoding-associated activation also was observed in the anterior cingulate (BA 32) and occipital (BA 17/18, 19) cortices; anterior cingulate (Fletcher et al. 1995; Kapur et al. 1996) and occipital (Kelley et al. 1998; Nyberg et al. 1996) activation has been reported previously during episodic memory encoding.

Significant encoding-associated activation was not observed in the medial temporal cortex. Although studies using novel or nonverbal stimuli have consistently shown medial temporal activation during encoding (Gabrieli et al. 1997; Haxby et al. 1996; Stern et al. 1996), studies with familiar verbal stimuli (similar to those used in the present study) have shown a less consistent pattern; whereas some studies (Alkire et al. 1998; Fernandez et al. 1998) have revealed medial temporal activation, others have not (Kapur et al. 1994; Shallice et al. 1994). However, given the small sample size, we cannot rule out the possibility that the absence of encoding-associated medial temporal activation in the present study is related to low statistical power.

\section{Triazolam-Induced Changes}

As predicted, triazolam produced a robust impairment in recognition memory for words presented during the encoding scans (Table 3); this finding replicates results of numerous studies demonstrating impaired memory
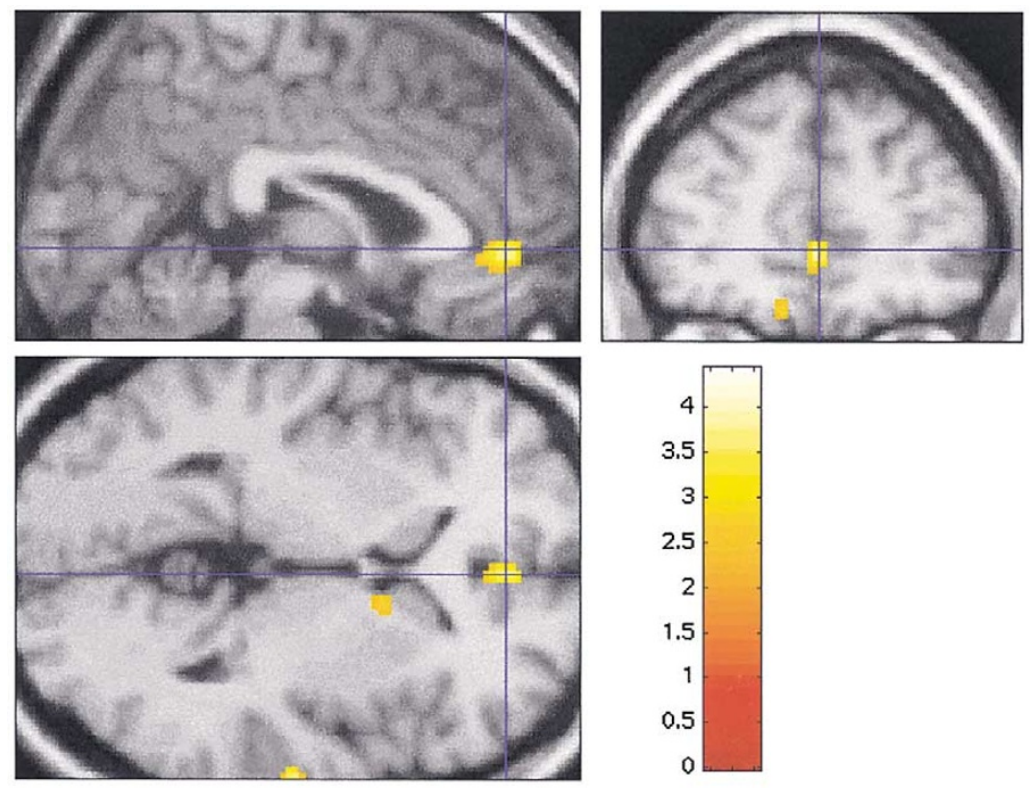

Figure 2. A statistical parametric map, showing regions of decreased activity in the triazolam condition relative to placebo during semantic categorization [measured by the interaction in $\mathrm{rCBF}$ between drug condition (triazolam vs. placebo) and task (semantic vs. orthographic categorization)], rendered onto sagittal (top left), coronal (top right) (image right is participant's right), and transverse (bottom) (image top is participant's left) sections of a stereotactically normalized structural MRI $(n=6)$. All voxels deactivated at $p \leqslant$ .01 , uncorrected, are shown; the color scale represents the significance level for deactivations from red (lowest) to yellow (highest). The coordinates $(2,46,0)$ were chosen to show a region in the right anterior cingulate (BA 32) that exhibited significant deactivation. 
performance with triazolam and other benzodiazepines (for reviews see Curran 1991; Duka et al. 1996; Polster 1993). However, to our knowledge, this is the first study to examine the brain activity associated with triazolam-induced memory impairment. Deactivation was observed in the triazolam condition relative to placebo during encoding [measured by the interaction in $\mathrm{rCBF}$ between drug condition (triazolam vs. placebo) and task (semantic vs. orthographic categorization)] in several regions that have been implicated as important to the process of encoding: precuneus (BA 7) (Krause et al. 1999), anterior cingulate cortex (BA 32) (Fletcher et al. 1995; Kapur et al. 1996), and cerebellum (Fernandez et al. 1998; Kopelman et al. 1998) (Table 4, Figure 2). Although activation in the precuneus has been observed more frequently during episodic memory retrieval than during encoding, results of a recent network analysis (Krause et al. 1999) indicate that the precuneus plays a role in both encoding and retrieval.

In addition to their involvement in episodic memory encoding, both the cerebellum and anterior cingulate cortex also have been implicated in higher-order attentional and executive functions (e.g., monitoring, organization, planning). The cerebellum shows activation during attentional tasks (Allen et al. 1997; Pardo et al. 1991), and results of a neuropsychological study suggest that the memory impairment exhibited by patients with relatively pure cerebellar degeneration is secondary to a deficit in executive functions (Appollonio et al. 1993). The anterior cingulate cortex also shows activation during attentional tasks (Barch et al. 2000; Coull et al. 1996), and is thought to be involved in initiation of behavior ("attention to action"; Posner et al. 1988), motivation, response selection, and inhibition of inappropriate responses (for a review, see Devinsky et al. 1995).

Given the putative role of the cerebellum and anterior cingulate cortex in higher-order functions, it is possible that the triazolam-induced deactivation in these regions reflects an impairment in episodic memory encoding that is secondary to an impairment in other functions (assuming the encoding task also demands greater use of these other functions than the control task). In fact, it is well documented that in addition to affecting memory, benzodiazepines also affect other functions, including attention, psychomotor performance, arousal, and mood (for reviews, see Hollister et al. 1993; Woods et al. 1992a). However, drug effects on memory remain statistically significant once effects on these other functions are partialed out statistically (Curran et al. 1991). Furthermore, a study by Curran et al. (1998) in which event-related potentials were recorded in participants receiving lorazepam, scopolamine, or diphenhydramine, provided evidence for dissociation of the effects of lorazepam (and scopolamine) on memory and arousal. Likewise, Coull et al. (1999) provided evidence for dissociation of diazepam's effects on mem- ory from those on executive function. The present study was not designed to dissociate effects of triazolam on encoding from those on other functions. However, analysis of performance during the semantic and orthographic categorization tasks indicates that participants were not impaired in their ability to direct attention to the tasks in the triazolam condition and did not perform worse on the semantic categorization task relative to orthographic categorization in either the placebo or triazolam condition. In fact, they displayed a high degree of accuracy (over 95\% correct) on both tasks in both the placebo and triazolam conditions. We, therefore, consider it unlikely that the changes in brain activity observed in this study in response to triazolam during memory encoding can be accounted for as a primary effect on attentional mechanisms. However, future studies designed to address this issue explicitly are necessary to dissociate triazolam-induced effects on memory encoding from those on other higher-order functions.

To our knowledge, no previous study has examined the brain substrates of triazolam-induced encoding impairment although two studies examined the brain activity associated with the impairment produced by other benzodiazepines (Bagary et al. 2000; Coull et al. 1999). Discrepancies in the results obtained in these three studies are likely related to the numerous methodological differences among the studies including differences in experimental design, nature of encoding and control tasks, type of stimuli, and benzodiazepine type, and dose level. Further research is necessary to reconcile these discrepancies.

It is possible that direct vascular effects of triazolam may have influenced assessment of changes in perfusion due to task performance. We think that this is unlikely, however, because benzodiazepines have not been shown to significantly affect factors that directly influence cerebral blood flow (e.g., blood viscosity, arterial vessel wall diameter) or blood pressure (cf. Mathew et al. 1992). Furthermore, we believe it is unlikely that direct effects on cerebral vasculature would yield the specific observed interaction between drug condition and task in encoding-associated regions; in fact, Friston (Friston et al. 1991, p. 87) have stated that regionally specific interactions between pharmacological and behavioral manipulations "must be dependent on neuronal activity" rather than on underlying vasculature (cf. also Friston et al. 1992).

The conclusions that can be drawn from the present study are somewhat limited by the small sample size of participants who completed both the placebo and triazolam sessions $(n=6)$. However, it should be noted that results of a PET- ${ }^{15} \mathrm{O}-\mathrm{H}_{2} \mathrm{O}$ study (Andreasen et al. 1996), which manipulated the size of the sample analyzed $(n=$ $33,16-17,11$, or $6-7)$ indicated that small sample sizes are associated primarily with increases in false-nega- 
tives rather than in false-positives. Thus, although a larger sample size might reveal additional brain regions associated with the triazolam-induced encoding impairment, we are confident in the reliability of the pattern of results observed in the present study.

To summarize, in addition to replicating (under placebo conditions) the pattern of brain activity observed in nonpharmacological encoding studies, results of this PET study suggest that the well-documented triazolaminduced encoding impairment is reliably associated with deactivation in a subset of encoding-associated regions.

\section{ACKNOWLEDGMENTS}

This project was partially supported by National Institute on Drug Abuse Research Grants DA-03889 and DA-11936. The authors thank Sue Boyer, Jennifer Bragg, Andrew Horti, and Varughese Kurian for technical assistance, John Yingling for computer programming assistance and technical support, and Stephen Francis, John Matochik, and Tim Mudric for assistance with data analysis.

\section{REFERENCES}

Alkire MT, Haier RJ, Fallon JH, Cahill L (1998): Hippocampal, but not amygdala, activity at encoding correlates with long-term, free recall of nonemotional information. Proc Natl Acad Sci USA 95:14506-14510

Allen G, Buxton RB, Wong EC, Courchesne E (1997): Attentional activation of the cerebellum independent of motor involvement. Science 275:1940-1943

Andreasen NC, Arndt S, Cizadlo T, O'Leary DS, Watkins GL, Boles Ponto LL, Hichwa RD (1996): Sample size and statistical power in $\left[{ }^{15} \mathrm{O}\right] \mathrm{H}_{2} \mathrm{O}$ studies of human cognition. J Cereb Blood Flow Metab 16:804-816

Appollonio IM, Grafman J, Schwartz V, Massaquoi S, Hallett M (1993): Memory in patients with cerebellar degeneration. Neurology 43:1536-1544

Bagary M, Fluck E, File SE, Joyce E, Lockwood G, Grasby P (2000): Is benzodiazepine-induced amnesia due to deactivation of the left prefrontal cortex? Psychopharmacology 150:292-299

Bailey DL, Jones T, Friston KJ, Colebatch JG, Frackowiak RSJ (1991): Physical validation of statistical parametric mapping. J Cereb Blood Flow Metab 11(Supp 2):S150

Barch DM, Braver TS, Sabb FW, Noll DC (2000): Anterior cingulate and the monitoring of response conflict: Evidence from an fMRI study of overt verb generation. J Cogn Neurosci 12:298-309

Brewer JB, Zhao Z, Glover GH, Gabrieli JDE (1998): Making memories: Brain activity that predicts whether visual experiences will be remembered or forgotten. Science 281:1185-1187

Buckner RL, Kelley WM, Petersen SE (1999): Frontal cortex contributes to human memory formation. Nature Neurosci 2:311-314
Cabeza R, Nyberg L (2000): Imaging cognition II: An empirical review of 275 PET and fMRI studies. J Cogn Neurosci 12:1-47

Coull JT, Frith CD, Dolan RJ (1999): Dissociating neuromodulatory effects of diazepam on episodic memory encoding and executive function. Psychopharmacology 145:213-222

Coull JT, Frith CD, Frackowiak RSJ, Grasby PM (1996): A frontoparietal network for rapid visual information processing: A PET study of sustained attention and working memory. Neuropsychologia 34:1085-1095

Craik FIM, Lockhart RS (1972): Levels of processing: A framework for memory research. J Verbal Learn Verbal Behav 11:671-684

Curran HV (1991): Benzodiazepines, memory, and mood: A review. Psychopharmacology 105:1-8

Curran HV, Pooviboonsuk P, Dalton JA, Lader MH (1998): Differentiating the effects of centrally acting drugs on arousal and memory: An event-related potential study of scopolamine, lorazepam, and diphenhydramine. Psychopharmacology 135:27-36

Curran HV, Schifano F, Lader M (1991): Models of memory dysfunction? A comparison of the effects of scopolamine and lorazepam on memory, psychomotor performance, and mood. Psychopharmacology 103:83-90

Demonet JF, Price C, Wise R, Frackowiak RSJ (1994): Differential activation of right and left posterior sylvian regions by semantic and phonological tasks: A positronemission tomography study in normal human subjects. Neurosci Lett 182:25-28

Devinsky O, Morrell MJ, Vogt BA (1995): Contributions of anterior cingulate cortex to behavior. Brain 118:279-306

Dolan RJ, Fletcher PC (1997): Dissociating prefrontal and hippocampal function in episodic memory encoding. Nature 388:582-585

Duka T, Curran HV, Rusted JM, Weingartner HJ (1996): Perspectives on cognitive psychopharmacology research. Behav Pharmacol 7:401-410

Endicott J, Spitzer RL (1978): A diagnostic interview: The schedule for affective disorders and schizophrenia. Arch Gen Psychiat 35:837-844

Fernandez G, Weyerts H, Schrader-Bolsche M, Tendolkar I, Smid HG, Tempelmann C, Hinrichs H, Scheich H, Elger CE, Mangun GR, Heinze HJ (1998): Successful verbal encoding into episodic memory engages the posterior hippocampus: A parametrically analyzed functional magnetic resonance imaging study. J Neurosci 18:18411847

Fernandez-Lopez A, Chinchetru MA, Fernandez PC (1997): The autoradiographic perspective of central benzodiazepine receptors: A short review. Gen Pharmacol 29:173180

Fletcher PC, Frith CD, Grasby PM, Shallice T, Frackowiak RSJ, Dolan RJ (1995): Brain systems for encoding and retrieval of auditory-verbal memory: An in vivo study in humans. Brain 118:401-416

Frey KA, Minoshima S, Koeppe RA, Kilbourn MR, Berger KL, Kuhl DE (1996): Stereotaxic summation analysis of human cerebral benzodiazepine binding maps. J Cereb Blood Flow Metab 16:409-417 
Friedman H, Greenblatt DJ, Burstein ES, Harmatz, Shader RI (1986): Population study of triazolam pharmacokinetics. Br J Clin Pharmacol 22:639-642

Friston KJ, Grasby P, Bench C, Frith C, Cowen P, Little P, Frackowiak RSJ, Dolan R (1992): Measuring the neuromodulatory effects of drugs in man with positron tomography. Neurosci Lett 141:106-110

Friston KJ, Grasby PM, Frith CD, Bench CJ, Dolan RJ, Cowen PJ, Little PF, Frackowiak RSJ (1991): The neurotransmitter basis of cognition: Psychopharmacological activation studies using positron emission tomography. In Wheelan and Chadwick (eds), Exploring Brain Functional Anatomy with Positron Tomography.(Ciba Foundation Symposium 163) Chichester, UK: Wiley, pp 76-92

Friston KJ, Holmes AP, Worsley KJ, Poline J-P, Frith CD, Frackowiak RSJ (1995): Statistical parametric maps in functional imaging: A general linear approach. Hum Brain Map 2:189-210

Gabrieli JDE, Brewer JB, Desmond JE, Glover GH (1997): Separate neural bases of two fundamental memory processes in the human medial temporal lobe. Science 276:264-266

Grady CL, McIntosh AR, Rajah MN, Craik FI (1998): Neural correlates of the episodic encoding of pictures and words. Proc Natl Acad Sci USA 95:2703-2708

Haxby JV, Ungerleider LG, Horwitz B, Maisog JM, Rapoport SL, Grady CL (1996): Face encoding and recognition in the human brain. Proc Natl Acad Sci USA 93:922-927

Hollister LE, Müller-Oerlinghausen B, Rickels K, Shader RI (1993): Clinical uses of benzodiazepines. J Clin Psychopharmacol 13:1S-169S

Kapur S, Craik FIM, Tulving E, Wilson AA, Houle S, Brown GM (1994): Neuroanatomical correlates of encoding in episodic memory: Levels of processing effect. Proc Natl Acad Sci USA 91:2008-2011

Kapur S, Tulving E, Cabeza R, McIntosh AR, Houle S, Craik FI (1996): The neural correlates of intentional learning of verbal materials: A PET study in humans. Brain Res Cogn Brain Res 4:243-249

Kelley WM, Miezin FM, McDermott KB, Buckner RL, Raichle ME, Cohen NJ, Ollinger JM, Akbudak E, Conturo TE, Snyder AZ, Petersen SE (1998): Hemispheric specialization in human dorsal frontal cortex and medial-temporal lobe for verbal and nonverbal memory encoding. Neuron 20:927-936

Kopelman MD, Stevens TG, Foli S, Grasby P (1998): PET activation of the medial-temporal lobe in learning. Brain 121(Pt 5):875-887

Krause BJ, Horwitz B, Taylor JG, Schmidt D, Mottaghy FM, Herzog H, Halsband U, Müller-Gärtner HW (1999): Network analysis in episodic encoding and retrieval of word-pair associates: A PET study. Eur J Neurosci 11:3293-3301

Leiner HC, Leiner AL, Dow RS (1995): The underestimated cerebellum. Hum Brain Map 2:244-254

London ED, Morgan MJ (1993): Positron emission tomography studies on the acute effects of psychoactive drugs on brain metabolism and mood. In London ED (ed), Imaging Drug Action in the Brain. Boca Raton, CRC Press, pp 265-280
Martin A, Wiggs CL, Weisberg J (1997): Modulation of human medial temporal lobe activity by form, meaning, and experience. Hippocampus 7:587-593

Mathew RJ, Wilson WH, Humphreys DF, Lowe JV, Wiethe KE (1992): Changes in cerebral blood velocity after intravenous diazepam. Biolog Psychiat 31:690-697

Millet P, Ibanez V, Delforge J, Pappata S, Guimon J (2000): Wavelet analysis of dynamic PET data: Application to the parametric imaging of benzodiazepine receptor concentration. Neuroimage 11:458-472

Mintzer MZ, Frey JM, Yingling JE, Griffiths RR (1997): Triazolam and zolpidem: A comparison of their psychomotor, cognitive, and subjective effects in healthy volunteers. Behav Pharmacol 8:561-574

Mintzer MZ, Griffiths RR (1999): Triazolam and zolpidem: Effects on human memory and attentional processes. Psychopharmacology 144:8-19

Mintzer MZ, Griffiths RR (2000): Acute effects of triazolam on false recognition. Mem Cognit 28:1357-1365

Mohler H, Okada T (1977): Benzodiazepine receptor: Demonstration in the central nervous system. Science 198:849-851

Nyberg L, Cabeza R, Tulving E (1996): PET studies of encoding and retrieval: The HERA model. Psychon Bull Rev 3:135-148

Nyberg L, Cabeza R, Tulving E (1998): Asymmetric frontal activation during episodic memory: What kind of specificity? Trends Cognit Sci 2:419-420

Pardo JV, Fox PT, Raichle ME (1991): Localization of a human system for sustained attention by positron emission tomography. Nature 349:61-63

Persson A, Ehrin E, Eriksson L, Farde L, Hedstrom C, Litton J, Mindus P, Sedvall G (1985): Imaging of [11C]-labeled Ro 15-1788 binding to benzodiazepine receptors in the human brain by positron emission tomography. J Psychiatr Res 19:609-622

Polster MR (1993): Drug-induced amnesia: Implications for cognitive neuropsychological investigations of memory. Psychol Rev 114:477-493

Posner MI, Petersen SE, Fox PT, Raichle ME (1988): Localization of cognitive operations in the human brain. Science 240:1627-1631

Posner MI, Raichle ME (1994): Images of Mind. New York, Scientific American Books

Raichle ME (1994): Images of mind: Studies with modern imaging techniques. Ann Rev Psychol 45:333-356

Rosier A, Cornette L, Dupont P, Bormans G, Michiels J, Mortelmans L, Orban GA (1997): Positron-emission tomography imaging of long-term shape recognition challenges. Proc Natl Acad Sci USA 94:7627-7632

Roy-Byrne P, Fleishaker J, Arnett C, Dubach M, Stewart J, Radant A, Veith R, Graham M (1993): Effects of acute and chronic alprazolam treatment on cerebral blood flow, memory, sedation, and plasma catecholamines. Neuropsychopharmacology 8:161-169

Shallice T, Fletcher P, Frith CD, Grasby P, Frackowiak RSJ, Dolan RJ (1994): Brain regions associated with acquisition and retrieval of verbal episodic memory. Nature 368:633-635 
Squires RF, Braestrup C (1977): Benzodiazepine receptors in rat brain. Nature 266:732-734

Stein EA, Risinger R, Bloom AS (2000): Functional MRI in pharmacology. In Moonen CTW, Bandettini PA (eds), Functional MRI. Berlin, Springer, pp 525-538

Stern CE, Corkin S, Gonzalez RG, Guimaraes AR, Baker JR, Jennings PJ, Carr CA, Sugiura RM, Vedantham V, Rosen BR (1996): The hippocampal formation participates in novel picture encoding: Evidence from functional magnetic resonance imaging. Proc Natl Acad Sci USA 93:8660-8665

Talairach J, Tournoux P (1988): A Co-planar Stereotactic Atlas of the Human Brain. Stuttgart, Thieme

Thorndike EL, Lorge I (1944): The Teacher's Word Book of 30,000 Words. New York: Teacher's College, Columbia University

Tulving E (1972): Episodic and semantic memory. In Tulving E, Donaldson W (eds), Organization of Memory. San Diego, Academic Press, pp 381-403

Tulving E (1983): Elements of Episodic Memory. New York, Oxford University Press

Tulving E, Kapur S, Craik FIM, Moscovitch M, Houle S (1994): Hemispheric encoding/retrieval asymmetry in episodic memory: Positron emission tomography findings. Proc Natl Acad Sci USA 91:2016-2020

Vandenberghe R, Price C, Wise R, Josephs O, Frackowiak RS
(1996): Functional anatomy of a common semantic system for words and pictures. Nature 383:254-256

Wagner AD, Schacter DL, Rotte M, Koutstaal W, Maril A, Dale AM, Rosen BR, Buckner RL (1998): Building memories: Remembering and forgetting of verbal experiences as predicted by brain activity. Science 281:11881191

Werry JS, Aman MG (1976): The reliability and diagnostic validity of the physical and neurological examination for soft signs (PANESS) J Autism Child Schizophr $6: 253-262$

Wise R, Chollet F, Hadar U, Friston K, Hoffner E, Frackowiak R (1991): Distribution of cortical neural networks involved in word comprehension and word retrieval. Brain 114:1803-1817

Woods JH, Katz JL, Winger G (1992a): Benzodiazepines: Use, abuse, and consequences. Pharmacol Rev 44:151347

Woods RP, Cherry SR, Mazziotta JC (1992b): Rapid automated algorithm for aligning and reslicing PET images. J Comput Assist Tomogr 16:620-633

Zachary RA, Paulson MJ, Gorsuch RL (1985): Estimating WAIS IQ from the Shipley Institute of Living Scale using continuously adjusted age norms. J Clin Psychol 41:820-831 